\title{
An Environmental History of the Civil War
}

Judkin Browning y Timothy Silver (2020).

Chapel Hill: University of North Carolina Press, 272 pp.

\section{4}

Nicolás Fernán Rey

Universidad del Salvador, Argentina

nicomics27@outlook.es

En los últimos años, la Historia ambiental se ha hecho un espacio en el campo historiográfico mundial. Si bien recientemente ha calado hondo en los académicos latinoamericanos, partió del mundo anglosajón en la década de los 70, especialmente de los Estados Unidos, de donde provienen los más distinguidos historiadores ambientales. Esta renovación ha permitido problematizar hechos que cuentan con amplios estudios bibliográficos, pero utilizando las herramientas metodológicas de la Historia ambiental. Tal es el caso del último trabajo de los historiadores Judkin Browning y Timothy Silver, An Environmental History of the Civil War, publicado en Estados Unidos por la editorial de la Universidad de Carolina del Norte en el año 2020. Los autores, especializados en Historia militar e Historia ambiental respectivamente, ponen de relieve las relaciones existentes entre la guerra civil estadounidense (un acontecimiento humano) y el mundo natural, tanto físico como biológico. De esta manera, buscan revelar el poder de agencia que tuvieron los microorganismos, los animales, el clima y la geografía en el acontecimiento estudiado. Como sostienen los autores, el trabajo intenta comprender los hechos interrelacionando las acciones desarrolladas por los humanos con el mundo natural. Además, visibilizan que así lo interpretaron algunos de los protagonistas de la contienda, pero no los historiadores de los casi 50.000 libros escritos sobre la Guerra de Secesión.

El trabajo se compone de un gran cuerpo bibliográfico, respaldado por memorias y cartas de generales y combatientes, y un archivo fotográfico que se distribuye a lo largo de la obra. La riqueza del volumen, como advierten los autores, no se centra en el uso de fuentes inéditas, sino en su interpretación en clave ambiental. Por un lado, los trabajos recientes del campo de las ciencias naturales brindan herramientas al historiador para reconstruir espacial y temporalmente el clima y el landscape de los años de beligerancia (1861-1865). Por otro lado, el desarrollo de la narración fluye en sintonía con el devenir del conflicto; si bien no pretende ser un relato lineal de los acontecimientos ni ahondar en los motivos de la contienda, es preciso señalar que el nivel de detalle de las campañas bélicas es alto, por lo que el lector requiere de ciertos conocimientos previos sobre la guerra entre unionistas y confederados. Dado lo expuesto anteriormente, el libro se divide en seis capítulos temáticos: Sickness, Weather, Food, Animals, Death and disability, Terrain y Epilogue: An Environmental Legacy, que buscan recuperar los sucesos biológicos y físicos que acompañaron y condicionaron el devenir de la guerra.

Los tres primeros capítulos, Sickness, Weather y Food, proponen repasar los acontecimientos sucedidos entre la primavera de 1861 y la de 1864, es decir, durante los años centrales del conflicto bélico. Este agrupamiento responde a la interrelación que poseen estos apartados, en tanto analizan las consecuencias físicas y biológicas del clima atípico que afectó gran parte de las campañas. La proliferación de enfermedades hídricas (waterborne illnesses), como el cólera o la fiebre amarilla, fue estimulada tanto por los efectos de eventos meteorológicos intensos, como el fenómeno La Niña y el ARkStorm, como también por cuestiones de logística (el atrincheramiento de las tropas en zonas anegables por largos períodos de tiempo). El manejo de comestibles y del agua potable, escasa en un ambiente insalubre pese a las abundantes precipitaciones sucedidas, dificultó aún más la logística de la guerra, intensificándose los saqueos y la 
destrucción de plantaciones aún inmaduras, lo que tendría como saldo la falta de alimento en el futuro inmediato.

De esta manera, la relación entre clima y enfermedades resultó ser un condicionante para la ejecución de ciertas maniobras bélicas, sobre todo en terrenos inundables como los de la cuenca del río Mississippi. La mezcla de lodo y agua, sumada a los desperdicios humanos y de animales que acompañaban a las tropas, dificultaron los avances y generaron escenas macabras, como la de gente ahogándose en arenas movedizas tras sucumbir bajo su propio peso por el fenómeno de la licuefacción. Los eventos humanos se ejecutan a la par de los eventos naturales, donde ya de por sí interactúan agentes biológicos y físicos. Como exponen los autores, el fracaso de la logística en algunas campañas se debió al desconocimiento de las fricciones que acontecen en los entornos naturales.

Los siguientes tres capítulos, Animals, Death and disability y Terrain, abarcan los últimos dos años de la contienda, cuando ya la balanza se inclinaba irremediablemente a favor de las tropas de la Unión, comandadas por Ulysses S. Grant. Por tal motivo, parte del análisis hace foco en los padecimientos de las tropas de ambos bandos, especialmente en aquellas regiones sureñas que defendían el lema confederado. El clima, la destrucción de las fuentes de alimento y el debilitamiento de las tropas a causa de las enfermedades traerían nuevas consecuencias que precipitarían el final de la secesión. Empero, el grueso del análisis nuevamente se centra en exponer el rol de agencia de seres biológicos y agentes físicos en el devenir de la guerra civil. La importancia de los caballos y de las mulas en los ejércitos del siglo XIX supuso no solo un problema para la logística en un entorno hostil como el que se expuso en el párrafo anterior, sino también un incremento del deterioro del aprovisionamiento de alimentos por la aparición de enfermedades zoonóticas y la merma de los animales de granja en los campos. Los autores ponen de relieve y remarcan que, si bien existía una conexión romantizada de los generales con los equinos, los civiles y las tropas generalmente trataban a estos animales de manera descartable.
Si la muerte de millones de animales causó estragos durante y después de la guerra, la muerte de aproximadamente 750.000 combatientes, sumada a miles de discapacitados, traería otros problemas. En el capítulo Death and disability, Browning y Silver analizan cuestiones culturales, como los problemas referidos al trato de los cadáveres. Mientras que los animales podían ser incinerados, los cuerpos de los fallecidos no podían serlo debido a las creencias religiosas. Asimismo, esto se relacionaba con la teoría miasmática en boga en la comunidad científica de la segunda mitad del siglo XIX, que asociaba los problemas de salubridad con los aromas fétidos esparcidos por los entes en descomposición que no lograban ser enterrados. Es que, con la muerte, diversos seres entran en interacción con los cuerpos. Desde ratas a pequeños microorganismos que aún se desconocían, los tejidos muertos eran espacio de vida y la preservación de los cuerpos en tal estado, si no podían ser inhumados, era una prioridad. Pese a ser un conflicto que estalló por cuestiones referidas a la abolición de la esclavitud, los combatientes tuvieron que hacerle frente a la realidad de que los cuerpos de blancos y de negros se infestaban por igual de gusanos. Por lo tanto, los embalsamadores prometían conservar los cuerpos "para que nunca se pongan negros".

Al igual que los cuerpos, que se alteraban súbitamente cuando entraban en contacto con otros seres biológicos, los terrenos eran entidades que poseían una lógica propia. Alterados tanto por las batallas como por procesos de largo término que escapaban por mucho a la propia existencia del ser humano, eran espacios de interacción que estaba sujetos, como sostenía el geógrafo marxista David Harvey, a los ritmos de la economía, la tecnología y la acción humana. Por tal motivo, una de las grandes consecuencias a largo plazo que se advierte de la guerra civil fue la creación de la pequeña parcela familiar en los antiguos latifundios sureños, que incentivó la sobre-explotación de la tierra, evitando la rotación de los cultivos para su recuperación. Los autores exponen que el fin de la esclavitud fue un consecuente directo de tal método productivo, que haría eco con fuerza en la década de 1930, cuando 
se produjo uno de los mayores desastres naturales de la historia de aquel país: el Dust Bowl.

En el epílogo, Browning y Silver realizan un recuento de las consecuencias de la guerra civil estadounidense a corto, mediano y largo plazo. Por ejemplo, destacan los progresos de las ciencias médicas y de las instituciones sanitarias debido al campo de prueba -como denunciaba Dalton Trumbo en su obra Johnny Got His Gun- que representaron los cuerpos de soldados heridos. No solo hubo impactos en el desarrollo de la meteorología o de la medicina, sino también en algunos hábitos culinarios, debido a la merma del ganado bovino en los estados sureños ocasionada por el conflicto: la cría de cerdos se multiplicó en los años posteriores, lo que impactó en una dieta mucho más rica en grasas, cuyas consecuencias se ven reflejadas hoy en día, en tanto estos estados poseen los mayores índices de sobrepeso y de colesterol en sangre. Por otra parte, la expansión hacia el oeste sobre las tierras de los pueblos originarios de América del Norte abrió nuevas expectativas, pero condujeron a que el gobierno federal, presidido por el veterano Ulysses
S. Grant, dictaminara la creación del Parque Nacional de Yellowstone para preservar aquel entorno natural prístino de la tan evidente e irreversible acción humana sobre bosques, cursos de aguas, tierra y animales.

En conclusión, esta última publicación de Judkin Browning y Timothy Silver brinda herramientas metodológicas a aquellos investigadores que deseen abordar sus trabajos desde la óptica de la Historia ambiental. Si bien se precisan nociones previas sobre la guerra civil estadounidense y sobre algunos temas y datos que son propios del campo de las ciencias naturales, el lector interesado en incursionar en esta corriente de la disciplina histórica podrá formularse nuevas preguntas en torno a la relación entre las sociedades humanas y el medio ambiente. La temática de este libro puede funcionar como disparador para quienes deseen realizar una historia ambiental de la Guerra del Paraguay, que atravesó dificultades climáticas, biológicas, geográficas y logísticas similares a las de la Guerra de Secesión durante la década de 1860. 